OPEN ACCESS

Edited by:

David Rodriguez-Lazaro,

University of Burgos, Spain

Reviewed by:

Elba Veronica Arias Rios,

IEH Laboratories \& Consulting Group,

United States

Michael Gänzle,

University of Alberta, Canada

*Correspondence:

Shiowshuh Sheen

shiowshuh.sheen@ars.usda.gov

Lee-Yan Sheen

lysheen@ntu.edu.tw

Specialty section:

This article was submitted to

Food Microbiology,

a section of the journal

Frontiers in Microbiology

Received: 16 January 2018

Accepted: 25 July 2018

Published: 14 August 2018

Citation:

Huang $C-Y$, Sheen S, Sommers $C$

and Sheen L-Y (2018) Modeling

the Survival of Escherichia coli

O157:H7 Under Hydrostatic

Pressure, Process Temperature, Time and Allyl Isothiocyanate Stresses

in Ground Chicken Meat.

Front. Microbiol. 9:1871.

doi: 10.3389/fmicb.2018.01871

\section{Modeling the Survival of Escherichia coli 0157:H7 Under Hydrostatic Pressure, Process Temperature, Time and Allyl Isothiocyanate Stresses in Ground Chicken Meat}

\author{
Chi-Yun Huang ${ }^{1,2}$, Shiowshuh Sheen ${ }^{2 *}$, Christopher Sommers ${ }^{2}$ and Lee-Yan Sheen ${ }^{1 *}$ \\ ${ }^{1}$ Institute of Food Science and Technology, National Taiwan University, Taipei, Taiwan, ${ }^{2}$ Eastern Regional Research Center, \\ Agricultural Research Service, United States Department of Agriculture, Wyndmoor, PA, United States
}

Shiga toxin-producing Escherichia coli O157:H7 (STEC) is a common contaminant in meat and poultry. We investigated the use of non-thermal high pressure processing (HPP), with or without allyl isothiocyanate (AITC) essential oil, to kill STEC in ground chicken meat. Temperature was found an important factor affecting the inactivation of STEC in addition to pressure and process time. A full factorial experiment design (4 factors $\times 2$ levels) was used to facilitate and evaluate the effect of pressure (250$350 \mathrm{MPa})$, operation temperature $\left(-15-4^{\circ} \mathrm{C}\right)$, AITC concentration $(0.05-0.15 \%, \mathrm{w} / \mathrm{w})$, and pressure-holding time (10-20 min) on the inactivation of STEC. A linear model (a polynomial equation) was developed to predict/describe those four parameters' impact on $E$. coli O157:H7 survival $\left(R^{2}=0.90\right)$, as well as a dimensionless non-linear model. Both types of models were validated with data obtained from separate experimental points. The dimensionless model also demonstrated that it may predict the lethality (defined as the log CFU/g reduction of STEC before and after treatment) reasonably well with some factors set slightly outside the design ranges (e.g., a wider application than the linear model). The results provide important information regarding STEC survival as affected by HPP (e.g., pressure, time and temperature) and AITC. With the addition of AITC, the hydrostatic pressure may be lowered to the 250-350 MPa level. Regulatory agencies and food industry may use those models for STEC risk assessment in ground chicken meat. A storage test (at 4 and $10^{\circ} \mathrm{C}, 10$ days) after HPP+AITC treatment indicated that AITC may continue depressing or killing the pressure-damaged cells.

Keywords: modeling, high pressure processing, allyl isothiocyanate, E. coli 0157:H7, ground chicken meat

\section{INTRODUCTION}

Shiga toxin-producing Escherichia coli O157:H7 (STEC O157:H7) is a troublesome foodborne pathogen associated with meat contamination. Gould et al. (2013) reported the most recent and comprehensive survey of the STEC from 2000 to 2010, in which the FoodNet sites showed 2006 cases of non-O157 STEC and 5688 cases of O157 STEC infections. During 2003-2012, 390 outbreaks related to E. coli $\mathrm{O} 157$ were reported and resulted in 4,928 illnesses, in which 1,272 
(26\% of illnesses) hospitalizations, and $33(0.7 \%)$ deaths. In these outbreaks, 255 outbreaks (255/390 or $65 \%$ ) were caused by foods (Heiman et al., 2015). Ground meat, e.g., beef and poultry, are also among STEC reservoirs in many countries. In 2015, a STEC O157:H7 outbreak associated with chicken salad involved seven states and several illness cases was reported (Centers for Disease Control and Prevention [CDC], 2015).

In the past 10 years, high hydrostatic pressure or high pressure processing (HPP), a non-thermal technology, has continuously advanced due to better machinery design and become a commercially feasible manufacturing means to attain microbial inactivation. The pressure range, $100-800 \mathrm{MPa}$ in combination with heat, the hurdle concept, has been investigated in numerous studies in recent years. HPP may enhance microbial inactivation without causing the detrimental changes to food color, flavor, nutritional content and sensory property with properly selected pressure level mostly likely at $400 \mathrm{MPa}$ and lower for meat applications (Hendrickx et al., 1998; San Martín et al., 2002; Olsen et al., 2010; Buckow et al., 2013). Liu et al. (2015) reported a 1-2 log reduction of multiple verotoxigenic and non-toxigenic $E$. coli isolates suspended in ground beef treated with HPP at $600 \mathrm{MPa}$ (3 min). Sheen et al. (2015) treated 39 individual STEC suspended in ground beef at $350 \mathrm{MPa}$ $\left(4^{\circ} \mathrm{C}\right)$ at multiple time points for up to $40 \mathrm{~min}$ using the USDA Food Safety Inspection Service (FSIS) accepted E. coli Petrifilms as the recovery medium to determine the $\mathrm{D}_{10}$ (i.e., time required to attain one log reduction) values. Ten minutes at $350 \mathrm{MPa}$ produced only a one $\log _{10}$ reduction of numerous STEC, in a study that used three independent experiments for each isolate, for statistical analysis (Vaux et al., 2012). Sommers et al. (2016) determined the HPP inactivation kinetics of a multi-isolate cocktail of Uropathogenic E. coli (UPEC) suspended in ground chicken at 300,400 , and $500 \mathrm{MPa}\left(4^{\circ} \mathrm{C}\right)$. The $D_{10}$ value for HPP was 30.6, 8.36, and $4.43 \mathrm{~min}$ for 300,400 , and $500 \mathrm{MPa}$, respectively, using $E$. coli Petrifilms as the recovery medium. Jiang et al. (2015) obtained ca. 2-4 log reduction of STEC suspended in ground beef using $4 \mathrm{~min} \times 1 \mathrm{~min}$ cycles of HPP followed recovery on either Tryptic Soy Agar (TSA) or Rainbow Agar O157. Bacterial injury was assessed ca. 10-40\%, in good agreement with results using non-selective Aerobic Plate Count Petrifilms vs. E. coli Petrifilms. Baccus-Taylor et al. (2015) indicated that combining HPP (400 $\mathrm{MPa})$ and temperature $\left(30^{\circ} \mathrm{C}\right)$, the reduction of cold-shocked E. coli O157:H7 could only reach $1 \log$ CFU/g. In general, HPP may deliver various pathogenic $E$. coli inactivation results in meats depending on the operation conditions and the media used to recover the survivals.

A few literatures are available with regard to application of HPP at low operation temperature $\left(<0^{\circ} \mathrm{C}\right)$ which could affect the microbial survivals, especially for foodborne pathogens. Black et al. (2010) reported that a HPP (400 MPa, $10 \mathrm{~min}$ ) followed by two different temperature treatments, i.e., at 20 and $-5^{\circ} \mathrm{C}$ (freezing), the reduction of E. coli $\mathrm{O} 157: \mathrm{H} 7$ may reach 3 and $1 \log \mathrm{CFU} / \mathrm{g}$, respectively. Maresca and Ferrari (2013, 2017) reported their results on STEC and Lactococcus lactis spp. suspended in liquid McIlvine buffer where significant levels of inactivation could be detected at pressure $>200 \mathrm{MPa}$ and temperature $<-20^{\circ} \mathrm{C}$. Urrutia et al. (2007) provided indepth information and concerns for food safety, quality, process parameters and consumer acceptance with the high-pressurelow-temperature (HPLT) processing. Luscher et al. (2004) reported that water showed an "unusual" freezing depression to $-22^{\circ} \mathrm{C}$ at $210 \mathrm{MPa}$. Three ice phases, i.e., I-III in a phase diagram of water under pressure, were presented to demonstrate the potential phase changes (solid/liquid or freezing/thawing) under high pressure. They concluded that the mechanism of Listeria innocua inactivation (3 $\log$ reduction at $200 \mathrm{MPa}$ ) in frozen suspension (buffer solution) was probably due to mechanical stress associated with phase transition. Massaux et al. (1999) studied the quality of pork meat affected by high hydrostatic pressure treatment indicating that freezing-thawing under a pressure of $100 \mathrm{MPa}$ is the most interesting process for pork meat - no exudate, reducing thawing time, slight discoloration and texture toughening observed. How and what would be the survival behaviors of STEC in different foods (involving proteins, fats and other ingredients) with HPP operated at high pressure (e.g., up to $400 \mathrm{MPa}$ ) and low temperature (e.g., $-15^{\circ} \mathrm{C}$ ) remain to be further explored.

Phytochemicals, i.e., ascorbic acid, carotenoids, flavonoids, folic acid, and tocopherol, are naturally and widely presented in plants, fruits, vegetables, and grains. Many studies have already demonstrated the nutritional benefits of phytochemicals to include strong antioxidant, anticancer, and antibacterial properties (Zhang et al., 2003). The antibacterial properties of these compounds are due to different functional groups including alkaloids, sulfur-containing groups, terpenoids, carotenoids, and polyphenols (Dias et al., 2012; Kelley et al., 2012; Park et al., 2013; Dusane et al., 2014; Amalya and Sumathy, 2015; Dwivedi et al., 2016; Moon and Rhee, 2016). Among those, 'wasabi', often used as a spice, contains a variety of phytochemicals, i.e., polyphenols, flavonoids, and allyl isothiocyanate (AITC). Previous studies have shown that AITC extracted from the dried seeds of Brassica nigra (black mustard) is the major antimicrobial constituent (Sultana et al., 2000; Merck, 2006). AITC also has been reported having antimicrobial (Kinae et al., 2000) and antioxidant activities (Lee et al., 2010). In addition, AITC may be used as the coating agent/film or built in packaging material to promote microbial inactivation to enhance food safety (Jin and Gurtler, 2011; Guo et al., 2013).

While an individual technology is too costly or have negative side-effects on food quality, a combination of two or more means, if properly selected, could result in a better outcome. For example, hydrostatic pressure level could be reduced by adding food-grade compounds (e.g., essential oils) to effectively enhance microbial food safety. The application of hurdle technology has become more popular in recent years to achieve multiple functions in food applications, e.g., to extend the shelf life and decrease the negative effect on food quality caused mainly by an individual technology. Somolinos et al. (2008) and Chien et al. (2017) studied the inactivation of E. coli by the combination of HPP and citral. Chien et al. (2016) reported the use of HPP and thymol in which STEC inactivation reached $5 \log$ at $400 \mathrm{MPa}, 20 \mathrm{~min}$ pressure time and $200 \mathrm{ppm}$ of thymol. Only are a few papers available in the literature discussing the complex impact of HPP 
and AITC concentration on E. coli O157:H7 survival in foods. $\mathrm{Li}$ and Gänzle (2016) studied and reported the inactivation of E. coli with combination of AITC and pressure (450 MPa for marinated beef or $600 \mathrm{MPa}$ for raw ground beef). They observed that the synergistic effect may only occur at AITC concentrations negatively effecting meat quality in beef. A storage test result at $4^{\circ} \mathrm{C}$ for $E$. coli was also reported.

When multiple parameters are involved in assessing a target response, mathematical modeling with proper experiment design may be the best means for the solution. Chien et al. (2016, 2017) and Sheen et al. (2018) developed linear and non-linear models to describe HPP inactivation on foodborne pathogens in combination with antimicrobial compounds and successfully demonstrated their results; therefore, similar methods were applied in this study. The objectives of this study were: (1) to evaluate the combination effects of HPP (hydrostatic pressure, operation temperature and time), and AITC concentration on the inactivation of E. coli O157:H7 in raw ground chicken meat; (2) to develop the four-parameter model which may properly predict the E. coli O157:H7 inactivation; and (3) to validate the model with experimental results.

\section{MATERIALS AND METHODS}

\section{Raw Ground Chicken Meat Preparation}

Raw ground lean chicken meat, with no additives (95\% lean, 5\% fat content) purchased at a local supermarket store (Wyndmoor, PA, United States) and delivered to lab (within $1 \mathrm{~h}$ ) in a cooler and separated into $90 \pm 5 \mathrm{~g}$ portions in polynylon pouches (Uline, Inc., Philadelphia, PA, United States) immediately. Those samples were vacuum sealed to 50 millibars using a Multi-Vac CN200 packager (Multi-Vac Inc., Kansas City, MO, United States), then frozen $\left(-20^{\circ} \mathrm{C}\right)$ for $24-48 \mathrm{~h}$, then gamma irradiated (Cs-137, $0.070 \mathrm{kGy} / \mathrm{min},-20^{\circ} \mathrm{C}$, Lockheed Georgia, Marietta, GA, United States) to a dose of $10 \mathrm{kGy}$ which inactivated any contaminating E. coli and background microflora. The irradiation-treated raw ground chicken meat showed similar lethality to the non-irradiated under HPP stress tested, e.g., the plate counts showed non-significant difference $(P>0.05)$ (Chien et al., 2016; Sheen et al., 2018). The irradiated ground chicken meat was maintained at $-20^{\circ} \mathrm{C}$ freezer. Ground chicken meat was defrosted overnight in a refrigerator $\left(4^{\circ} \mathrm{C}\right)$ prior to experiment procedures. Every batch of the gamma irradiated ground chicken meat was tested with TSA and non-selective petrifilm to verify that none cell count was detected.

\section{STEC 0157:H7 Isolates and Cocktail}

Three E. coli O157:H7 (strains: C9490, 59762 and 59768) available and purchased from the American Type Culture Collection (ATCC, Manassas, VA, United States) were used. Those isolates were individually stored at $-80^{\circ} \mathrm{C}$ freezer. Each strain was propagated on the Sorbitol MacConkey agar at $37^{\circ} \mathrm{C}, 24 \mathrm{~h}$ and then stored at $4^{\circ} \mathrm{C}$ ready for use. One day before the experiment, a loopful of each strain was individually transferred to $10 \mathrm{ml}$ Tryptic Soy Broth without glucose (TSB, BD/Difco) and held in an orbital shaker (Model G34, New Brunswick Scientific, Edison,
NJ, United States) maintained at $37^{\circ} \mathrm{C} / 150-180 \mathrm{rpm} / 20 \mathrm{~h}$; then harvested via centrifugation at $2400 \times g / 15 \mathrm{~min} / 4.0^{\circ} \mathrm{C}$, (Model Z-206A, Hermle Labortechnik, Germany) and re-suspended in $20 \mathrm{ml}$ of $0.1 \%$ sterile peptone water (SPW, BD/Difco) to form the three-isolate cocktail. Each culture contained $10^{8-9} \mathrm{CFU} / \mathrm{ml}$. Fresh cocktails were prepared for each experiment.

\section{High Pressure Processing (HPP) Treatments}

Hsu et al. (2015) described the details of HPP operation using a laboratory scale unit (Mini Food lab FPG5620, Stansted Fluid Power Ltd., Essex, United Kingdom) with a temperature control device set-up which was used in this study. When temperature below $0^{\circ} \mathrm{C}$ was needed, e.g., -15 to $0^{\circ} \mathrm{C}$, the sample temperature was controlled by the chiller set at the targeted temperature. The tested sample temperature was further monitored by an additional T-type thermocouple (Proline RP 855, Lauda, Germany) to ensure the operation and food temperature deviation within $\pm 1^{\circ} \mathrm{C}$ of set point except during the pressure come-up and release periods. All the temperature profiles showed that no thermal effects from the HPP process (i.e., $<20^{\circ} \mathrm{C}$ in all cases). In current study with $350 \mathrm{MPa} / 10 \mathrm{~min} /-15^{\circ} \mathrm{C}$ conditions (for example), the initial temperature was set at $-15^{\circ} \mathrm{C}$. When compression started (time at $0 \mathrm{~s}$ ), temperature rose to $10^{\circ} \mathrm{C}$ at $50 \mathrm{~s}$ (peak temperature), then gradually went down to $0^{\circ} \mathrm{C}$ at $130 \mathrm{~s}$, continuously decreased to $-13^{\circ} \mathrm{C}$ at $330 \mathrm{~s}$ and stayed steadily at $-13^{\circ} \mathrm{C}$ until decompression began at $600 \mathrm{~s}$. Temperature then dropped to $-20^{\circ} \mathrm{C}$ for $3-5 \mathrm{~s}$ and rose back to $-13^{\circ} \mathrm{C}$ (while operation completed). The temperature/time profiles (in general) were similar to that reported by Hsu et al. (2015).

\section{The Full Factorial Design (FFD)}

To effectively investigate the four factor interactions and facilitate model development, an experimental design is needed to assist in performance of the inactivation study. Therefore, a Full Factorial Design combining four parameters was selected. Those factors included operation temperature (may involve freezing/thawing phase change in food under high pressure), hydrostatic pressure, pressure-holding time, and AITC concentration. The combinations with each factor at two levels (high and low to cover the selected range) were shown in Table 1. For HPP, optimal pressure was focused on 250-350 $\mathrm{MPa}$, and holding times at 10-20 min. To select AITC concentration ranges, a sensory test for odor changes of ground chicken meat up to $0.15 \%(w / w)$ was conducted and found acceptable by a group of 5 lab staff. A more in-detail sensory evaluation is planned in a future study. Massaux et al. (1999) and Luscher et al. (2004) discussed and demonstrated that water freezing/thawing under high pressure may involve several ice polymorph transition and formation, its true impact on foodborne pathogen inactivation and quality damage in food matrices (e.g., meat) remains to be further investigated. They reported that inactivation of L. innocua was progressing rapidly during pressure holding under liquid conditions, whereas in the ice phases, extended pressure holding times had comparatively little effect. With the complexity of meat undergoing freezing/thawing at high pressure 
and limited information available, the phase-change (in foods) impact on a microbial inactivation (i.e., E. coli O157:H7) may be evaluated through the FFD data/result in which individual parameter and their interaction effects on the targeted objective (i.e., inactivation) can be estimated via a properly developed model. Modeling provides an effective tool to solve this kind of challenging problem.

In addition to the 16 combinations $\left(2^{4}\right.$ for 4 -factor $\times 2$-level; coded +1 and -1 for high and low, respectively), a combination factors at center level (coded 0) was also selected and performed at the beginning and end of the FFD. There were total 18 sets of experiments used to develop the models. Each combination of the full factorial design was performed three times independently (Vaux et al., 2012) with two duplicated samples $(3 \times 2$ data collected).

\section{Preparation of Ground Chicken Meat for HPP Treatment}

Allyl isothiocyanate ( $\geq 95 \%$ FCC, Sigma-Aldrich, St. Louis, MO, United States), density $1.01 \mathrm{~g} / \mathrm{ml}$, was purchased and kept in dark/cool area. Thawed ground chicken meat $(5 \mathrm{~g})$ was weighed and aseptically transferred into $2 \mathrm{oz}$ (Nasco Co., Fort Atkinson, WI, United States) Whirl-Pak bag/pouch; the targeted AITC concentration was pipetted and added directly into raw meat, hand-mixed for 20-30 s, then inoculated with $0.5 \mathrm{ml}$ of cocktail, mixed manually for another $30 \mathrm{~s}$, and sealed to 50 millibars using the Multi-Vac CN200 packager. Ten pouches were layout flat then, vacuum sealed again in a polynylon bag (Uline, Inc., Philadelphia, PA, United States) as a secondary barrier to prevent the potential contamination to HPP unit. The samples were stored at $4^{\circ} \mathrm{C}$ while awaiting HPP treatment, if needed due to the HPP unit capacity. The waiting time was controlled to less than $30 \mathrm{~min}$. Each HPP treatment was repeated in triplicate for each of the 16 combinations in a full factorial design plus the two center points.

\section{E. coli 0157:H7 Enumeration}

Ground chicken meat (5 g) samples were combined with $45 \mathrm{ml}$ of $0.1 \% \mathrm{SPW}$ and stomached for $2 \mathrm{~min}$ (Model 400C, Seward, Basingstoke, United Kingdom). Following proper decimal dilutions with $0.1 \%$ SPW, $1.0 \mathrm{ml}$ of diluted sample was placed on duplicate E. coli/coliform Petrifilm ${ }^{\mathrm{TM}}(3 \mathrm{M}$ Microbiology Products Co., St. Paul, MN, United States). Chien et al. $(2016,2017)$ reported that there was not significant different in survival counts among TSA plates, E. coli/coliform Petrifilm ${ }^{\mathrm{TM}}$ and non-selective APC Petrifilm. The films were maintained at

TABLE 1 | Factors and levels for two-level factorial design.

\begin{tabular}{lcccc}
\hline Factor & Levels & Low level & Middle & High level \\
\cline { 2 - 5 } & Units & $\mathbf{- 1}$ & $\mathbf{0}$ & $\mathbf{+ 1}$ \\
\hline Temperature & ${ }^{\circ} \mathrm{C}$ & -15 & -5 & 4 \\
Pressure & $\mathrm{MPa}$ & 250 & 300 & 350 \\
Time & Minute & 10 & 15 & 20 \\
AlTC concentration $(\%)$ & $\%(\mathrm{w} / \mathrm{w})$ & 0.05 & 0.10 & 0.15
\end{tabular}

room temperature for at least $6 \mathrm{~h}$ to allow the injured cells to recover (Huang, 2004), and then incubated at $37^{\circ} \mathrm{C}$ for $24 \mathrm{~h}$. The TSA plate counts and non-selective APC petrifilm were slightly higher (ca. $0.5 \log \mathrm{CFU} / \mathrm{g}$ ) than those from selective $3 \mathrm{M}$ Petrifilm, which also has been approved/used by USDA-Food Safety Inspection Service (USDA Food Safety and Inspection Service [FSIS], 2012) for recovery of E. coli. However, if the actual survival count is needed for food safety consideration, the most conservative means/counts (a worst case scenario approach) may apply. Colonies were counted by the $3 \mathrm{M}$ Petrifilm ${ }^{\mathrm{TM}}$ plate reader (Model 6499, 3M Health Care, 3M Center, St. Paul, MN, United States) and presented as log CFU/g.

\section{Statistical Analyses and Model Development}

The results/data were analyzed by one-way analysis of variation (ANOVA) and Duncan's multiple range tests (SAS v9.4) with $p<0.05$ as the significance criterion. The lethality, or survival ratio, of E. coli O157:H7 was measured in terms of the log reduction [i.e., $\log \left(N_{\mathrm{o}} / N\right)=\log N_{\mathrm{o}}-\log N$ ] where $N_{\mathrm{o}}$ and $N$ are the initial and survival cell counts before and after test, respectively. Statistical analysis using the general linear regression and non-linear regression procedures in SAS software (SAS v9.4, SAS Institute Inc., Cary, NC, United States) was applied to perform the data evaluation and model construction. The full factorial design is used in modeling to include terms of individual parameter, interactions of two, three, or more parameters and etc. There were many interaction terms for a four-parameter system and among those terms only significant at $P<0.05$ were selected for inclusion. The dimensionless non-linear model, based on Sheen's model formula, was also developed to predict the inactivation of E. coli O157:H7 (Zhou et al., 2015; Chien et al., 2016, 2017).

\section{Model Performance and Validation}

Model performance may be evaluated using the experimental data vs. the predicted values. In the current case, there were 18 data points in the full factorial design which may serve for this purpose. A total 54 data set $(18 \times 3$ duplicates $)$ were plotted to examine how the data were bounded in the $\pm 95 \%$ confidence interval limits.

In order to evaluate and validate the developed models, several parameter combinations within the four parameter ranges were selected to justify the linear and non-linear models. Generally speaking, the dimensionless non-linear model may cover wider parameter ranges to predict E. coli O157:H7 inactivation. Therefore, we also selected several parameter combinations slightly outside the factor design ranges to further evaluate the prediction accuracy of the dimensionless non-linear model.

\section{E. coli 0157:H7 Storage Test}

To better understand the bacterial growth potential of E. coli O157:H7 in poultry meat during storage (e.g., shelf life application), ground chicken meat sample pouches prepared following the same procedures mentioned before and treated with $300 \mathrm{MPa}, 15 \mathrm{~min}$ at $4^{\circ} \mathrm{C}$ were used. After HPP, the samples 
were stored at 4 and $10^{\circ} \mathrm{C}$ for $9-10$ days. The populations of E. coli $\mathrm{O} 157: \mathrm{H} 7$ in the samples were determined at selected day during the storage period (HPP treated date marked as day 1) using both selective and non-selective media as mentioned previously. The temperature at 4 or $10^{\circ} \mathrm{C}$ was to simulate the refrigerated storage or abuse condition, respectively. All groups were performed in triplicate randomly. The detection limit was $1.0 \log \mathrm{CFU} / \mathrm{g}$.

\section{RESULTS}

There were many preliminary experiments needed to determine the range of each parameter required to facilitate model development. Any single parameter having too-wide and/or too-narrow range may make the model construction task difficult or impossible. Therefore, the final selected parameter ranges may be slightly different than those individually tested. It is also interesting to note that AITC alone with concentration $0.05-0.15 \%$ showed little impact on E. coli O157:H7 inactivation in ground chicken meat. The performance of essential oils as inactivation enhancer may largely depend on food system and the actual impact confirmed only through experimentation.

\section{Physical Changes of Ground Chicken Meat - Visual Observation}

The color and texture of ground chicken meat treated at 300 and $350 \mathrm{MPa}$ were similar to those of untreated vacuumpackaged ground chicken meat. The raw ground chicken meat's texture may start to deteriorate and became softer or mushy and eventually lose integrity at pressure $\geq 450 \mathrm{MPa}$. However, no visible color change was noticed with the addition of $0.05-0.20 \%$ AITC following a 2 weeks $\left(4\right.$ and $10^{\circ} \mathrm{C}$ ) storage period. Detailed experiments in texture changes will be investigated in the future.

\section{Hydrostatic Pressure Impact on E. coli 0157:H7 Survival}

Table 2 shows the log reductions (lethality) of E. coli O157:H7, resulting from $\mathrm{HPP}\left(200-400 \mathrm{MPa}\right.$, at $50 \mathrm{MPa}$ intervals) at $4^{\circ} \mathrm{C}$ for $15 \mathrm{~min}$. The $E$. coli $\mathrm{O} 157: \mathrm{H7}$ reduction ranged from 0.43 (200 MPa), $0.88(250 \mathrm{MPa}), 1.76 \mathrm{log} \mathrm{CFU} / \mathrm{g}$ (300 MPa), 2.10 $\log \mathrm{CFU} / \mathrm{g}(350 \mathrm{MPa})$ to $2.67 \mathrm{CFU} / \mathrm{g}(400 \mathrm{MPa})$. The ANOVA

TABLE 2 | Logarithmic reductions of $E$. coli O157:H7 on ground chicken meat after different hydrostatic pressure treatments at $4^{\circ} \mathrm{C}$ and $15 \mathrm{~min}$ (without AITC added).

\begin{tabular}{lc}
\hline Pressur (MPa) & Inactivation $\log \boldsymbol{N}_{\mathbf{o}}-\log \boldsymbol{N}$ \\
\hline 400 & $2.67 \pm 0.02$ \\
350 & $2.10 \pm 0.08$ \\
300 & $1.76 \pm 0.07$ \\
250 & $0.88 \pm 0.11$ \\
200 & $0.43 \pm 0.01$
\end{tabular}

The detection limit was $1.0 \mathrm{log}$ CFU/g. Results are shown as mean \pm standard deviation ( $N=3$ random runs; 2 duplicates/run; $n=2 \times 3$ ). showed that significant dependence of reduction on MPa level $(P<0.05)$. This result further confirm that at low pressure level (e.g., $200 \mathrm{MPa}$ ), there is little inactivation.

\section{Allyl Isothiocyanate Impact on E. coli 0157:H7 Survival}

Table 3 shows the log reductions of $E$. coli $\mathrm{O} 157: \mathrm{H} 7$ with different AITC concentration treatments (i.e., $0.05-0.25 \%$ ) at $4^{\circ} \mathrm{C}$ and $24 \mathrm{~h}$. None of the AITC concentrations showed significant effect on E. coli O157:H7 inactivation, where the ANOVA indicated $p>0.05$ and all the lethality was negligible $(<0.5 \log \mathrm{CFU} / \mathrm{g})$.

\section{Hydrostatic Pressure and Temperature $\left(-15\right.$ to $\left.7^{\circ} \mathrm{C}\right)$ Impact on $\mathrm{E}$. coli $0157: \mathrm{H7}$ Survival}

Figure 1 shows the log reduction of E. coli O157: H7, resulting from the treatment with three different pressures $(300,350$, and $400 \mathrm{MPa})$ and five temperatures $\left(-15,-4,0,4\right.$, and $\left.7^{\circ} \mathrm{C}\right)$ in $15 \mathrm{~min}$. The reduction of $\mathrm{E}$. coli $\mathrm{O} 157: \mathrm{H} 7$ at $-15,-4,0$, 4 , and $7^{\circ} \mathrm{C}$ operation temperature was found $1.45-2.55,2.04-$ 2.48, 2.37-3.92, 1.76-2.67, and 1.48-2.94 log CFU/g, respectively. It was also observed that the reduction of E. coli O157:H7 at $0^{\circ} \mathrm{C}$ is higher than the other temperatures tested at 350 and $400 \mathrm{MPa}$. However, at $300 \mathrm{MPa}$ level, the difference could become less significant. The selected temperature range certainly induces multiple phase changes - freezing and thawing before and after temperature treatment at $-15^{\circ} \mathrm{C}$; thawing and freezing during compression and decompression, respectively. The phasechange under high pressure influenced further complicates the evaluation of temperature impact on microbial survival. The -15 and $4^{\circ} \mathrm{C}$ were selected as the low and high end points to take advantage of treated products may be transferred to freezer and refrigerated storage, respectively, without further temperature treatment.

\section{HPP (Pressure, Temperature, and Time) and AITC Impact on E. coli 0157:H7 Survival}

In order to effectively evaluate the four parameters, i.e., hydrostatic pressure, operation temperature, pressure holding time and AITC concentration, impact on E. coli O157:H7 survival, a 2-level FFD was performed, i.e., Table 4 where -1 and +1 indicate the lower and upper parameter level, respectively.

TABLE 3 | Reductions of Escherichia coli $\mathrm{O} 157: \mathrm{H} 7$ on ground chicken meat after different AITC concentration (\%) treated for $24 \mathrm{~h}$.

\begin{tabular}{lc}
\hline AITC concentrate (\%) & Inactivation $\log N_{\mathbf{o}}-\log \boldsymbol{N}$ \\
\hline 0.05 & $0.26 \pm 0.15$ \\
0.10 & $0.15 \pm 0.06$ \\
0.15 & $0.19 \pm 0.06$ \\
0.20 & $0.21 \pm 0.05$ \\
0.25 & $0.35 \pm 0.10$
\end{tabular}

The detection limit was $1.0 \mathrm{log}$ CFU/g. Results are shown as mean \pm standard deviation ( $N=3$, with 2 petrifilm counts per run; $n=2 \times 3$ random runs). 


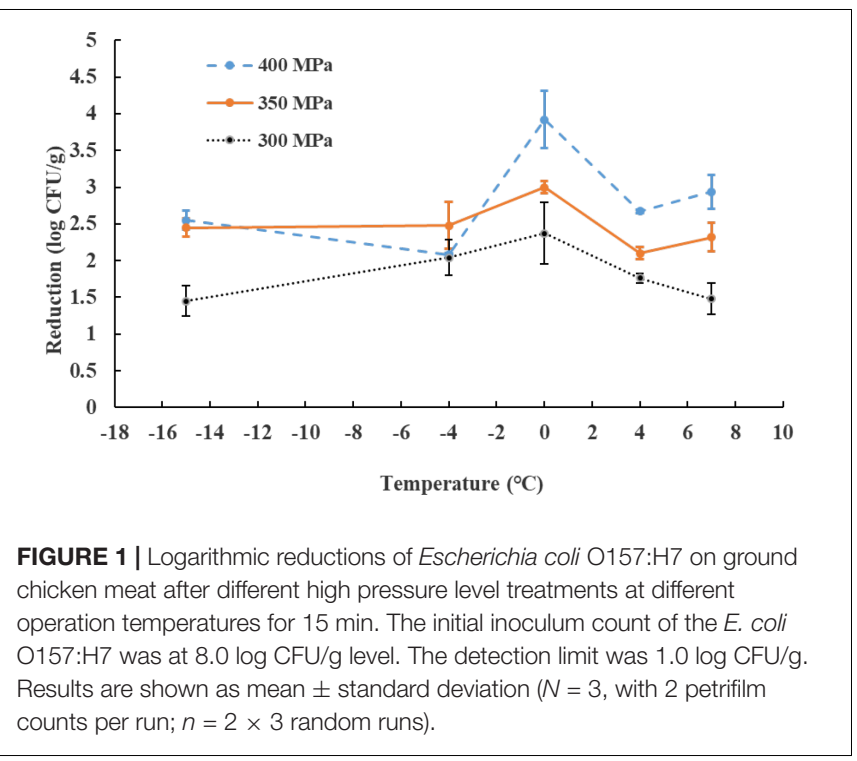

No. 1 and No. 18 were added with all parameters at midlevel in the model development process which may enhance model prediction performance. With HPP initially set at 300$400 \mathrm{MPa}$ range, the $400 \mathrm{MPa}$ combination constantly showed an overwhelming reduction result. Therefore, the pressure range was adjusted down to 250-350 MPa then it was possible to implement and complete the model development.

The reduction of E. coli O157:H7 ranged from 0.85 to $7.25 \mathrm{log}$ $\mathrm{CFU} / \mathrm{g}$ in the full factorial design. When hydrostatic pressure level, AITC concentration and pressure-holding time increased, the E. coli O157:H7 survival decreased.

\section{Linear Model for E. coli 0157:H7 Survival}

General Regression Analysis (forward or backward stepwise) of a 4-factor, 2-level full factorial experimental design may generate the following equation for the pathogen inactivation calculation (cell count reduction).

$$
\begin{aligned}
\log \left(N_{\mathrm{o}} / N\right)= & Y=B_{0}+B_{1} \cdot P+B_{2} \cdot C+B_{3} \cdot t+B_{4} \cdot T \\
& +B_{5} \cdot P \cdot C+B_{6} \cdot P \cdot t+B_{7} \cdot P \cdot T+B_{8} \cdot C \cdot t \\
& +B_{9} \cdot C \cdot T+B_{10} \cdot t \cdot T+B_{11} \cdot P^{2}+B_{12} \cdot C^{2} \\
& +B_{13} \cdot t^{2}+B_{14} \cdot T^{2}+\cdots+B_{15} \cdot P^{3}+B n \cdot T^{3}
\end{aligned}
$$

In Eq. (1), $Y$ is the dependent target function or dependent variable. $B_{\mathrm{i}(0-\mathrm{N})}$ is the regression constant for each corresponding term to be determined via regression procedures. The polynomial linear model therefore, developed to predict the E. coli O157:H7 inactivation amount/quantity is shown in the following equation (2) using the PROC GLM procedure (SAS v9.4).

E. coli O157: $\mathrm{H7}$ reduction $\left(Y=\log N_{\mathrm{o}} / N\right)$ :

\begin{tabular}{|c|c|c|c|c|c|}
\hline Trail no. & Temperature celsius (level) & Pressure MPa (level) & Time minute (level) & $\begin{array}{l}\text { AITC concentration } \\
(\%) \%(w / w) \text { (level) }\end{array}$ & $\begin{array}{c}\text { Inactivation } \log N_{\mathrm{o}}-\log N \\
\text { E. coli 0157:H7 }\end{array}$ \\
\hline 1 & $-5(0)$ & $300(0)$ & $15(0)$ & $0.10(0)$ & $3.82 \pm 0.31$ \\
\hline 2 & $-15(-1)$ & $250(-1)$ & $10(-1)$ & $0.05(-1)$ & $1.34 \pm 0.08$ \\
\hline 3 & $4(+1)$ & $250(-1)$ & $10(-1)$ & $0.05(-1)$ & $0.85 \pm 0.08$ \\
\hline 4 & $-15(-1)$ & $350(+1)$ & $10(-1)$ & $0.05(-1)$ & $2.72 \pm 0.29$ \\
\hline 7 & $4(+1)$ & $250(-1)$ & $20(+1)$ & $0.05(-1)$ & $1.60 \pm 0.02$ \\
\hline 8 & $-15(-1)$ & $350(+1)$ & $20(+1)$ & $0.05(-1)$ & $6.38 \pm 0.26$ \\
\hline 9 & $4(+1)$ & $350(+1)$ & $20(+1)$ & $0.05(-1)$ & $2.88 \pm 0.12$ \\
\hline 10 & $-15(-1)$ & $250(-1)$ & $10(-1)$ & $0.15(+1)$ & $2.43 \pm 0.21$ \\
\hline 11 & $4(+1)$ & $250(-1)$ & $10(-1)$ & $0.15(+1)$ & $2.00 \pm 0.17$ \\
\hline 16 & $-15(-1)$ & $350(+1)$ & $20(+1)$ & $0.15(+1)$ & $7.18 \pm 0.04$ \\
\hline 17 & $4(+1)$ & $350(+1)$ & $20(+1)$ & $0.15(+1)$ & $7.25 \pm 0.09$ \\
\hline 18 & $-5(0)$ & $300(0)$ & $15(0)$ & $0.10(0)$ & $3.20 \pm 0.15$ \\
\hline
\end{tabular}

$$
\begin{aligned}
Y & =6.19509-0.07290 \cdot P-0.81711 \cdot C+0.25242 \cdot t \\
& +0.03140 \cdot T+0.07450 \cdot P \cdot C-0.00055 \cdot P \cdot t
\end{aligned}
$$

TABLE 4 | Logarithmic reductions of E. coli O157:H7 on ground chicken meat after high pressure processing treatments according to the four-parameter, two-level factorial design.

(16 design combinations +2 center points at nos. 1 and 18). The initial inoculum count of the E. coli O157:H7 was 8.10 log CFU/g. The detection limit was 1.0 log CFU/g. Results are shown as mean \pm standard deviation ( $N=3$ random runs; with 2 duplicates/run; $n=2 \times 3$ data per combination). 


$$
\begin{aligned}
& -0.00025 \cdot P \cdot T+0.72167 \cdot C \cdot t+0.79386 \cdot C \cdot T \\
& -0.00411 \cdot t \cdot T+0.00016 \cdot P^{2}
\end{aligned}
$$

$R^{2}=0.90$

Where, $Y: \log$ cell reduction in terms of the $\log \mathrm{CFU} / \mathrm{g}$ difference at before and after stress treatment presented as lethality per our definition in the Abstract; $P$ : Pressure (MPa); $C$ : AITC concentration (\%, weight basis); $t$ : pressure-holding time (minute); $T$ : temperature $\left({ }^{\circ} \mathrm{C}\right)$. The second order of $C$, $t$, and $T$ terms, cubic and higher order terms were found not significant $(P>>0.05)$ in general regression analyses (GLM, SAS), therefore, those terms are all excluded. The regression analysis further confirmed that operation temperature is a significant factor in Eq. (2) where the $T$ term having $p=0.0233$ and interaction terms, i.e., $P \cdot T, C \cdot T, t \cdot T$, all showing $p<0.05$.

\section{Non-linear Model for E. coli O157: H7 Survival}

According to Zhou et al. (2015), Sheen's dimensionless nonlinear model is a useful application to simplify a model which

\section{A O157:H7 (linear model)}

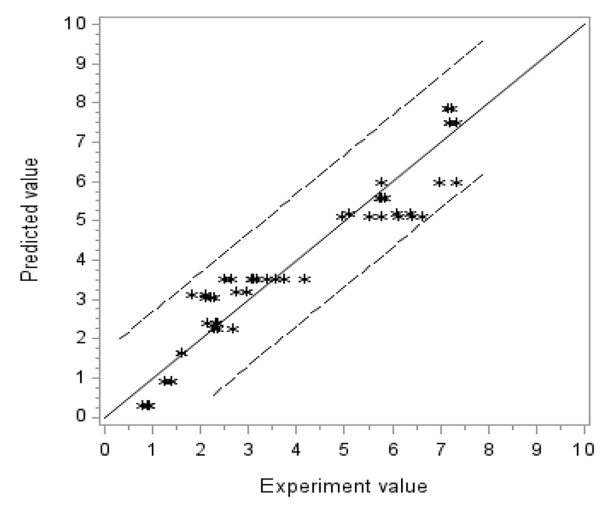

B O157:H7 (dimensionless nonlinear model)

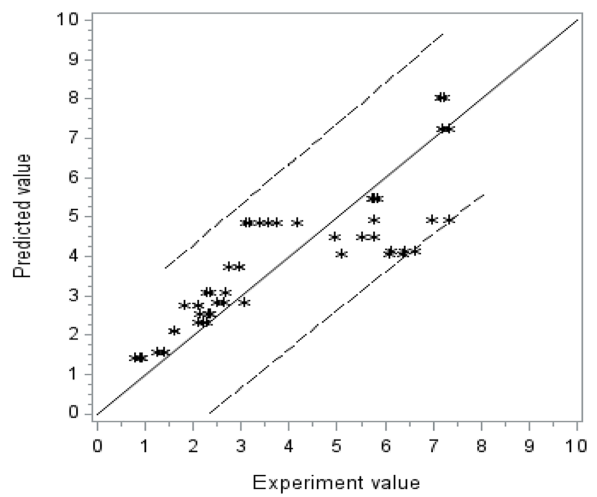

FIGURE 2 | The experiment vs. predicted lethality (log CFU/g reduction) using (A) polynomial linear and (B) dimensionless non-linear models (Sheen's model). may involve multiple parameters. Using the non-linear regression procedure in SAS v9.4, the model developed is shown in the following equation (3):

E. coli O157: $\mathrm{H7}$ reduction $\left(Z=\log N_{\mathrm{o}} / N\right)$ :

$$
\begin{gathered}
Z=29.5243 \cdot\left[\frac{P-200}{P+200}\right]^{0.6417} \cdot\left[\frac{C-0.04}{C+0.04}\right]^{0.4005} \\
\cdot\left[\frac{t-5.0}{t+5.0}\right]^{0.6544} \cdot\left[\frac{20-T}{20+T}\right]^{0.0441}
\end{gathered}
$$

$F$-value $=159.72 ; \operatorname{Pr}>F(<0.0001)$;

Sum of Squares Error and Sum of Squares Uncorrected Total are 61.2894 and 1060.2 , respectively.

Where, 200, 0.04, 5.0, and 20 are the pressure $P$, AITC concentration $C$, pressure-holding time $t$, and temperature $T$, respectively, selected from experiment observations to represent a potential maximum or minimum limit of a parameter. The $F$-values and $\operatorname{Pr}>F$-values (used in non-linear regression) indicated the equation is a good fit of the data set. Figure 2 shows the observed experimental values versus predicted ones for the polynomial linear model (A) and Sheen's dimensionless non-linear model $(\mathrm{B})$. The solid line $($ slope $=1)$ indicates where the predicted data match the observed experimental ones. If the predicted data are over- or underestimated, the data points should be above or below the solid line, respectively. From Figure 2, both types of models showed good fit within the $95 \%$ confidence limits. Since the $95 \%$ confidence interval in (B) is slightly wider than (A), it is expected that predicted values using the linear model may be somewhat better than the non-linear model. As mentioned previously, the non-linear model may have the potential of applications where parameters set slightly outside the FFD ranges.

\section{Model Performance and Validation}

The experimental values were found in good agreement with the predicted values from Eq. (2) to Eq. (3). Model performance was validated by the four key parameters at combinations of $\mathrm{HPP} /$ temperature/AITC concentration/time such as $280 \mathrm{MPa} /-6^{\circ} \mathrm{C} / 0.14 \% / 16 \mathrm{~min}, 320 \mathrm{MPa} / 2{ }^{\circ} \mathrm{C} / 0.12 \% / 13 \mathrm{~min}$, $340 \mathrm{MPa} /-12^{\circ} \mathrm{C} / 0.15 \% / 12 \mathrm{~min}$ and $260 \mathrm{MPa} / 4^{\circ} \mathrm{C} / 0.15 \% / 10 \mathrm{~min}$ (all within the full factorial design ranges). Table 5 presented the log reduction (experimental vs. predicted), both models (Run $\# 1$, \#2, \#3, and \#4) showed predictions with derivation within 10 and $25 \%$ for both the linear and non-linear models, respectively. The developed models were proven to be reasonably accurate for predicting the inactivation of E. coli $\mathrm{O} 157: \mathrm{H} 7$ in ground chicken meat with treatment parameters in the range of $-15-4^{\circ} \mathrm{C}$, 250-350 $\mathrm{MPa}, 0.05-0.15 \%$ and $10-20 \mathrm{~min}$. In addition, we further evaluated the dimensionless non-linear model with some factors set outside design ranges, e.g., Run \#5: $270 \mathrm{MPa} / 6$ ${ }^{\circ} \mathrm{C} / 0.2 \% / 18 \mathrm{~min}$, Run \#6: $260 \mathrm{MPa} / 10^{\circ} \mathrm{C} / 0.13 \% / 25 \mathrm{~min}$, Run \#7: $380 \mathrm{MPa} / 2^{\circ} \mathrm{C} / 0.2 \% / 12$ min and Run \#8: $250 \mathrm{MPa} / 12^{\circ} \mathrm{C} / 0.18 \% / 15 \mathrm{~min}$. The experimental vs. predicted values for Run \#5/\#6/\#7/\#8 values were 4.31/4.12/6.44/3.31 (experiment) and 4.95/4.53/6.57/3.59 (predicted by Eq. 3) log 
TABLE 5 | Verification of predictive models (Eq. 2 and Eq. 3) for log reduction of E. coli O157:H7 in raw ground chicken meat.

\begin{tabular}{|c|c|c|c|c|c|c|c|}
\hline \multirow[t]{3}{*}{ Run } & \multicolumn{4}{|c|}{ Parameter } & \multicolumn{3}{|c|}{$\log _{10}$ reduction $(C F U / g)^{a}$} \\
\hline & \multirow[t]{2}{*}{ Temperature $\left({ }^{\circ} \mathrm{C}\right)$} & \multirow[t]{2}{*}{ Pressure (MPa) } & \multirow[t]{2}{*}{ AITC concentration (\%) } & \multirow[t]{2}{*}{ Time (minute) } & \multicolumn{3}{|c|}{$\log N_{\circ}-\log N$} \\
\hline & & & & & Experiment & Predict (Eq. 2) & Predict (Eq. 3) \\
\hline 1 & -6 & 280 & 0.14 & 16 & $4.01 \pm 0.44$ & 4.28 & 4.97 \\
\hline 2 & 2 & 320 & 0.12 & 13 & $4.11 \pm 0.74$ & 4.12 & 5.09 \\
\hline 3 & -12 & 340 & 0.15 & 12 & $5.79 \pm 0.14$ & 5.47 & 5.93 \\
\hline 4 & 4 & 260 & 0.15 & 10 & $3.23 \pm 0.46$ & 3.19 & 3.07 \\
\hline 5 & 6 & 270 & 0.2 & 18 & $4.31 \pm 0.08$ & & 4.95 \\
\hline 6 & 10 & 260 & 0.13 & 25 & $4.12 \pm 0.41$ & & 4.53 \\
\hline 7 & 2 & 380 & 0.2 & 12 & $6.44 \pm 0.57$ & & 6.57 \\
\hline 8 & 12 & 250 & 0.18 & 15 & $3.31 \pm 0.16$ & & 3.59 \\
\hline
\end{tabular}

alnitial populations of E. coli 0157:H7 was at $8.0 \mathrm{log}$ CFU/g level. The detection limit was $1.0 \mathrm{log}$ CFU/g.

reduction of E. coli O157:H7, respectively, and all discrepancies were within 15\% (Table 5).

\section{E. coli 0157:H7 Storage}

Storage studies were conducted to determine the effect of the treatment parameters on E. coli O157:H7 survival. The storage test after treatment was performed in $7-10$ day periods at $4^{\circ} \mathrm{C}(\mathrm{a}$ typical refrigeration condition) and the cell counts were recorded at selected time interval. The results showed in Figure 3, with four factor conditions set at $0.12 \%$ AITC concentration, $300 \mathrm{MPa}$, $15 \mathrm{~min}$ at $4^{\circ} \mathrm{C}$. After HPP processing, the samples were stored at $4^{\circ} \mathrm{C}$ for 10 days. The initial E. coli $\mathrm{O} 157: \mathrm{H} 7$ number without treatment was at $8 \log \mathrm{CFU} / \mathrm{g}$ level. After the treatment at 1, 2, 3, $4,5,7,8$, and 10 days during the storage period, the survival E. coli O157:H7 were $3.74,3.72,4.2,4.13,3.31,2.77,2.76$, and $1.41 \log$ $\mathrm{CFU} / \mathrm{g}$, respectively. The cell population was slightly increased (by $0.5 \log \mathrm{CFU} / \mathrm{g}$ at days 3 and 4) but still within the testing error, then, decreased to1.4 $\log \mathrm{CFU} / \mathrm{g}$ at day 10 and under the detecion limit at day $21(<1.0 \log \mathrm{CFU} / \mathrm{g}$, datum not shown). It showed that AITC remained active and continously killed the damaged cells in this study. At abuse storage temperature, e.g., $10^{\circ} \mathrm{C}$, a similar decreasing trend was observed but at a slightly slower rate and was under the detection limit at day 21 . The E. coli survival counts were also tested on the non-selective media and results showed consistent trend having about $0.5 \log \mathrm{CFU} / \mathrm{g}$ higher than selective $3 \mathrm{M}$ petrifilm (data not shown). Our ground chicken meat was treated with gamma irradiation to eliminate the background microbe noise which was tested/verified using TSA and non-selective petrifilm. Therefore, a proper combination of HPP and AITC may be able to deliver the 5-log CFU/g reduction during low temperature storage.

\section{DISCUSSION}

Escherichia coli O157:H7 survival behavior in response to HPP intervention included four parameters, i.e., hydrostatic pressure, process time, process temperature and AITC concentration, was investigated via an experimental design that further facilitated model development. High hydrostatic pressure (in terms of HPP)

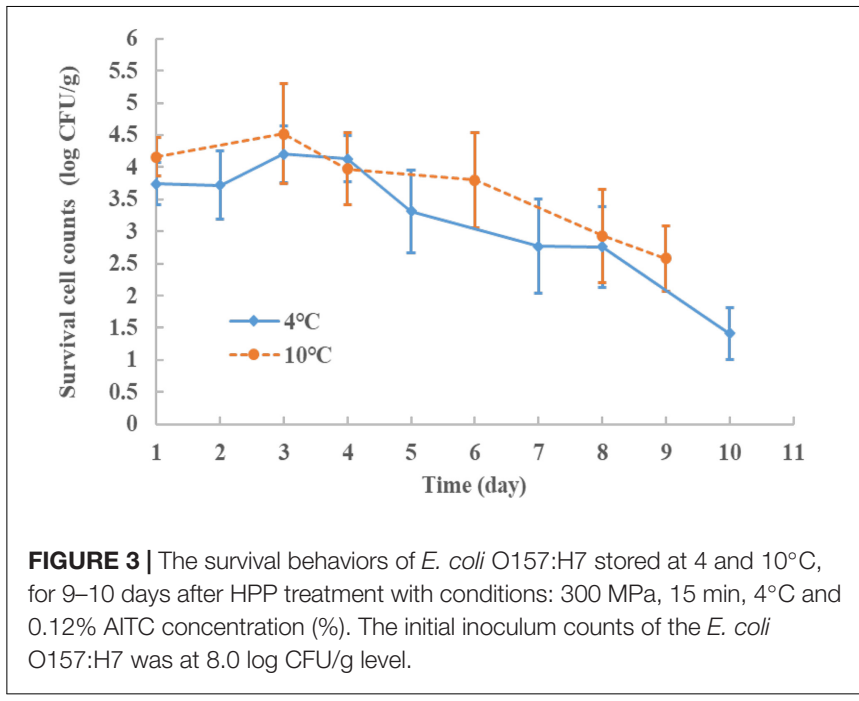

recently became a commercially feasible processing method to achieve the foodborne pathogens inactivation (Balasubramaniam et al., 2015) in certain foods thanks to the advancement in machinery design. However, raw meat texture and quality showed significantly visible change/damage in our study at $400-450 \mathrm{MPa}$ which inspired the incorporation of natural food-grade essential oils (i.e., AITC) and, therefore, applying a lower hydrostatic pressure to increase microbial inactivation. Del Olmo et al. (2010) and Simonin et al. (2012) reviewed and reported that meat (poultry) quality was affected by high hydrostatic pressure at $400 \mathrm{MPa}$ and higher pressure levels which is similar to our observations. Several studies also have reported that, in HPP alone experiments, meat quality (beef) was damaged at pressure level higher than 400-450 MPa (McArdle et al., 2010, 2011). To achieve optimal lethality (e.g., $>5$ log reduction) of E. coli O157:H7 through those complicated interactions it can only be attempted via a proper experiment design and mathematical analyses or model development. HPP alone may cause certain level of lethality for E. coli O157:H7, which was found in the range of $1-3 \log \mathrm{CFU} / \mathrm{g}(300-400 \mathrm{MPa})$ in $10-15 \mathrm{~min}$. The HPP 
alone $(<400 \mathrm{MPa}$ and $<15 \mathrm{~min})$ cannot achieve a $5 \log \mathrm{CFU} / \mathrm{g}$ reduction of $E$. coli $\mathrm{O} 157: \mathrm{H} 7$.

Previous studies showed that combining the HPP (400$600 \mathrm{MPa})$ and temperature $\left(-5\right.$ to $\left.30^{\circ} \mathrm{C}\right)$ with different processing time (1-20 $\mathrm{min}$ ) may inactivate $1-3 \log$ of several E. coli strains in foods (Black et al., 2010; Omer et al., 2010; Baccus-Taylor et al., 2015). On the other hand, almost no literature focused on the impact of low HPP operation temperature (e.g., -15 to $5^{\circ} \mathrm{C}$ ) on microbial survival to include foodborne E. coli $\mathrm{O} 157: \mathrm{H7}$ in meat which may involve phase change (i.e., freezing/thawing) stages. The freezing/thawing of free water in food matrix under high hydrostatic pressure could be very complicated (e.g., phase change temperature might be shifted) and only a few publications (for meat) are available for this physical change phenomenon and its impact on microbial survival. We may assume that the phase change could occur in a fast path and ice crystal size might play some (unclear) role to cause cell structure damage - this should be a very interesting subject for further research. Since temperature and pressure are both important parameters and their impact including interaction is not well investigated yet, a proper experimental design was applied to develop the empirical model which may take into account the phase change effect on $E$. coli inactivation. Model development technology is a powerful method/tool in solving the complicated multi-parameter problem to achieve the challenging scientific/engineering result. Furthermore, the results also provides another possibility for commercial raw meat application, i.e., to choose an optimized temperature range in order to achieve the higher E. coli O157:H7 inactivations and reduce the after processing storage cost at or below refrigeration. Lethality affected by operation temperature may only appear in some food systems and AITC addition might further enhance the temperature effect.

Lu et al. (2016) showed that AITC had strong antibacterial property and high potential to effectively control E. coli O157:H7 in TSB when the concentration reached $1000 \mu \mathrm{g} / \mathrm{ml}$. However, the AITC antibacterial efficiency did not cause significant difference when concentration was below $1000 \mu \mathrm{g} / \mathrm{ml}$ level. The antibacterial potentiality was found very weak without other hurdle used even when AITC concentration reached $0.25 \%$ (Table 3) which is much different from $\mathrm{Lu}$ et al. (2016) study. Our result indicates that the effect of AITC (or similar compounds) on foodborne pathogen inactivation should be carefully examined in actual targeted foods with selected experiment parameters/conditions and appropriate bacterial growth/recovery medium.

Hurdle technology is gaining in popularity in food processing in recent years due to its potential for extending the shelf-life and reducing negative change to food texture. For food safety concern to meet the 'pasteurization' status of non-thermal process such as HPP (National Advisory Committee on Microbiological Criteria for Food [NACMCF], 2006), HPP in couple with other processing means/aids to achieve a $5-\log \mathrm{CFU} / \mathrm{g}$ reduction of foodborne pathogen may be required (Liu et al., 2012; Huang et al., 2013). Furthermore, the cost of HPP operation is affected by high pressure levels, holding time and temperature. It is highly desirable to optimize (minimize) the operation cost with food quality and microbial safety factors included (Bover-Cid et al., 2011). In our study, HPP alone (350 $\left.\mathrm{MPa}, 4^{\circ} \mathrm{C}\right)$ in $15 \mathrm{~min}$ can only attain a $2.1 \log \mathrm{CFU} / \mathrm{g}$ reduction of E. coli O157:H7 (Figure 1). Combining $\mathrm{HPP}$ at $350 \mathrm{MPa}, 20 \mathrm{~min}$ at $4^{\circ} \mathrm{C}$ with $0.15 \%$ AITC concentration, a greater than $5 \log$ reduction was obtained (Table 4).

High pressure processing may cause sublethal injury in bacteria (Wesche et al., 2009), where the cell membrane is a primary site of pressure damage (Yuste et al., 2004). The membrane damaged cells may show enhanced sensitivity to antimicrobials (Hauben et al., 1998). It has been reported that AITC can cause membrane damage which resulting the membrane became more permeable and increasing the leakage of cellular metabolites (Lin et al., 2000), the essential oil can also inhibit enzyme activities in E. coli O157:H7. Luciano and Holley (2009) reported three potential functions of AITC including (1) it is more effective at low $\mathrm{pH}$ and degradation reduces antimicrobial activity; (2) decomposition products in water lost antimicrobial function; (3) it may have multi-targeted action mechanisms inhibiting several metabolic pathways and damaging cell structures.

Gänzle and Liu (2015) pointed out that some surviving cells (e.g., E. coli O157:H7) after HPP treatment may be able to repair the sublethal damage in suitable growth conditions to cause safety issue. In order to mitigate this concern with proving the concept that AITC surviving HPP may remain functional (i.e., active) to kill damaged cells, a storage test (up to 10 days) to observe how the cells would survive during 4 or $10^{\circ} \mathrm{C}$ was performed. Figure 3 showed the survival counts of the $\mathrm{E}$. coli $\mathrm{O} 157: \mathrm{H} 7$ were reduced to 3.50-4.20 log CFU/g after HPP, and could drop to $1.41 \mathrm{log}$ CFU/g in 10 days at $4^{\circ} \mathrm{C}$ storage (typical refrigerated temperature). A similar trend was observed at $10^{\circ} \mathrm{C}$ for abuse temperature case. Based on the storage study results, pressure-damaged cells (E. coli $\mathrm{O} 157: \mathrm{H7}$ ) in chicken meat after HPP+AITC treatment were found not able to recover. Therefore, combining the HPP and AITC, we found the hurdle effect on ground chicken meat can achieve an inactivation of E. coli. O157:H7 to $>5 \log \mathrm{CFU} / \mathrm{g}$ with lower pressure levels and AITC concentrations in this study. There could be some strains with higher resistance to pressure stress in which a 5 log CFU/g reduction may not be achieved.

Reliable mathematical models (linear and dimensionless nonlinear) provide several advantages which include estimating the objective (i.e., cell count reduction) without doing experiment (another cost saving). Our models may also provide the useful means to locate/select the HPP operation conditions (i.e., $<350 \mathrm{MPa}$ ) with a greater than $5 \log \mathrm{CFU} / \mathrm{g}$ lethality achieved or implemented. Furthermore, the dimensionless non-linear model showed potential applications and reliable predictions with parameters slightly outside the designed limits (accuracy in $15 \%$ error vs. experiment data, Table 5, No. 5, 6, 7, and 8) which may expand its parameter application ranges. The users should apply those empirical models carefully to consider equipment, microbial strains, food matrix and other factors not to exceed those parameter boundaries. The model parameters may change as soon as a different type (or even batch) of meat is used. 
Until further validation, the model is valid only for the type of meat and equipment for which it was validated.

\section{CONCLUSION}

The complicate interactions from four parameters which deliver complex and important impact on E. coli O157:H7 lethality in raw ground chicken meat under HPP stress can be expressed by the linear regression and/or dimensionless non-linear models (Sheen's model). The identified key parameters include pressure (250-350 $\mathrm{MPa})$, operation temperature $\left(-15-4^{\circ} \mathrm{C}\right)$, AITC concentration $(0.05-0.15 \%, \mathrm{w} / \mathrm{w})$, and pressure-holding time (10-20 $\mathrm{min})$, where the pressure level is lower than those needed and used in the meat industry $(>450 \mathrm{MPa})$ to achieve a 5-log $\mathrm{CFU} / \mathrm{g}$ lethality. The reduced pressure level $(\leq 350 \mathrm{MPa})$ may also play an important role in effectively reducing the meat quality and/or texture damage. With the current developed method,

\section{REFERENCES}

Amalya, J. T. J., and Sumathy, J. H. V. (2015). Antimicrobial and anticancer activity of the leaf, flower and carotenoid extracts of Peltophorum petrocarpum. Int. J. Curr. Trends Pharm. Res. 3, 748-753.

Baccus-Taylor, G. S., Falloon, O. C., and Henry, N. (2015). Pressure resistance of cold-shocked Escherichia coli O157:H7 in ground beef, beef gravy and peptone water. J. Appl. Microbiol. 118, 1521-1529. doi: 10.1111/jam.12794

Balasubramaniam, V. M., Martinez-Monteagudo, S. I., and Gupta, R. (2015). Principles and application of high pressure-based technologies in the food industry. Ann. Rev. Food Sci. Technol. 6, 435-462. doi: 10.1146/annurev-food022814-015539

Black, E. P., Hirneisen, K. A., Hoover, D. G., and Kniel, K. E. (2010). Fate of Escherichia coli O157:H7 in ground beef following high-pressure processing and freezing. J. Appl. Microbiol. 108, 1352-1360. doi: 10.1111/j.1365-2672.2009. 04532.x

Bover-Cid, S., Belletti, N., Garriga, M., and Aymerich, T. (2011). Model for Listeria monocytogenes inactivation on dry-cured ham by high hydrostatic pressure processing. Food Microbiol. 28, 804-809. doi: 10.1016/j.fm.2010.05.005

Buckow, R., Sikes, A., and Tume, R. (2013). Effect of high pressure on physcicochemical properties of meat. Crit. Rev. Food Sci. Nutr. 53, 770-786. doi: $10.1080 / 10408398.2011 .560296$

Centers for Disease Control and Prevention [CDC] (2015) Multistate outbreak of Shiga toxin-producing Escherichia coli O157:H7 infections linked to Costco rotisserie chicken salad (Final Update). Available at: https://www.cdc.gov/ecoli/ 2015/o157h7-11-15/index.html [accessed November 28, 2017].

Chien, S. Y., Sheen S., Sommers, C. H., and Sheen, L. Y. (2016). Modeling the inactivation of intestinal pathogenic Escherichia coli O157:H7 and uropathogenic E. coli in ground chicken by high pressure processing and thymol. Front Microbiol. 7:920. doi: 10.3389/fmicb.2016.00920

Chien, S. Y., Sheen, S., Sommers, C. H., and Sheen, L. Y. (2017). Modeling the inactivation of Escherichia coli O157:H7 and uropathogenic E. coli in ground beef by high pressure processing and citral. Food Control. 71, 371-375. doi: 10.1016/j.foodcont.2016.09.017

Del Olmo, A., Morales, P., Ávila, M., Calzada, J., and Nuñez, M. (2010). Effect of single-cycle and multiple-cycle high-pressure treatments on the colour and texture of chicken breasts fillets. Innov. Food Sci. Emerg. Technol. 11, 441-444 doi: 10.1016/j.ifset.2010.01.012

Dias, C., Aires, A. N., Bennett, R. A. S., Rosa, E. J., Saavedra, M., (2012). First study on antimicriobial activity and synergy between isothiocyanates and antibiotics against selected Gram-negative and Gram-positive pathogenic bacteria from clinical and animal source. Med. Chem. 8, 474-480. doi: 10.2174/ 1573406411208030474

Dusane, D. H., Hosseinidoust, Z., Asadishad, B., and Tufenkji, N. (2014). Alkaloids modulate motility, biofilm formation and antibiotic susceptibility of meat quality may be much improved and potential operation cost reduced. The HPP process optimization is also feasible via model application.

\section{AUTHOR CONTRIBUTIONS}

$\mathrm{C}-\mathrm{YH}$ completed the experiment, data analyses, and initial writeup. SS supported lab facility, tools, advice and submitted the manuscript. CS provided information, uropathogenic E. coli strains, and feedback. L-YS provided general advice to student $\mathrm{C}-\mathrm{YH}$.

\section{FUNDING}

This project was funded by USDA-ARS National Program 108 Food Safety Project No. 8072-42000-078-00D.

uropathogenic Escherichia coli. PLoS One 9:e112093. doi: 10.1371/journal.pone. 0112093

Dwivedi, G. R., Tiwari, N., Singh, A., Kumar, A., Roy, S., and Negi, A. S. (2016). Gallic acid-based indanone derivative interacts synergistically with tetracycline by inhibiting efflux pump in multidrug resistant E. coli. Appl. Microbiol. Biotechnol. 100, 2311-2325. doi: 10.1007/s00253-015-7152-6

Gänzle, M., and Liu, Y. (2015). Mechanisms of pressure-mediated cell death and injury in Escherichia coli: from fundamentals to food applications. Front. Microbiol. 6:599. doi: 10.3389/fmicb.2015.00599

Gould, L. H., Mody, R. K., Ong, K. L., Clogher, P., Cronquist, A. B., Garman, K. N., et al. (2013). Increased recognition of non-O157 Shiga toxin-producing Escherichia coli infections in the United States during 2000-2010: epidemiologic features and comparison with E. coli O157 Infections. Foodborne Pathog. Dis. 10, 453-460. doi: 10.1089/fpd.2012.1401

Guo, M., Jin, T. Z., Scullen, O. J., and Sommers, C. H. (2013). Effects of antimicrobial coatings and cryogenic freezing on survival and growth of Listeria innocua on frofen ready-to-eat shrimp during thawing. J. Food Sci. 78, 195-200. doi: 10.1111/1750-3841.12180

Hauben, K. J., Bernaerts, K., and Michiels, C. W. (1998). Protective effect of calcium on inactivation of Escherichia coli by high hydrostatic pressure. J. Appl. Microbiol. 85, 678-684. doi: 10.1111/j.1365-2672.1998. 00577.x

Heiman, K. E., Mody, R. K., Johnson, S. D., Griffin, P. M., and Gould, L. H. (2015). Escherichia coli $\mathrm{O} 157$ Outbreaks in the United States, 2003-2012. Emerg. Infect. Dis 21, 1293-1301. doi: 10.3201/eid2108.141364

Hendrickx, M., Ludykhuyze, L., VandenBroeck, I., and Weemaes, C. (1998). Effects of high pressure on enzymes related to food quality. Trends Food Sci. Technol. 9, 197-203.doi: 10.1016/S0924-2244(98)00039-9

Hsu, H., Sheen, S., Sites, J., Cassidy, J., Scullen, B., and Sommers, C. (2015). Effect of high pressure processing on the survival of Shiga toxin-producing Escherichia coli (Big Six vs. O157:H7) in ground beef. Food Microbiol. 48, 1-7. doi: 10.1016/j.fm.2014.12.002

Huang, L. (2004). Thermal resistance of Listeria monocytogenes, Salmonella heidelberg, and Escherichia coli O157:H7 at elevated temperatures. J. Food Prot. 67, 1666-1670. doi: 10.4315/0362-028X-67.8.1666

Huang, Y., Ye, M., and Chen, H. (2013). Inactivation of Escherichia coli O157:H7and Salmonella spp. in strawberry puree by high hydrostatic pressure with/without subsequent frozen storage. Int. J. Food Microbiol.160, 337343.doi: 10.1016/j.ijfoodmicro.2012.11.008

Jiang, Y., Scheinberg, J. A., Senevirathne, R., and Cutter, C. N. (2015). The efficacy of short and repeated high-pressure processing treatments on the reduction of non-O157:H7 Shiga-toxin producing Escherichia coli in ground beef patties. Meat Sci. 102, 22-26. doi: 10.1016/j.meatsci.2014.12.001

Jin, T., and Gurtler, J. B. (2011). Inactivation of Salmonella in liquid egg albumen by antimicrobial bottle coatings infused with allyl isothiocyanate, nisin and zine 
oxide nanoparticles. J. Appl Microbiol. 110, 704-712. doi: 10.1111/j.1365-2672. 2011.04938.x

Kelley, C., Zhang, Y., Parhi, A., Kaul, M., Pilch, D.S., and LaVoie, E.J. (2012). 3-Phenyl substituted 6, 7-dimethoxyisoquinoline derivatives as FtsZ-targeting antibacterial agents. Bioorg. Med. Chem. 20, 7012-7029. doi: 10.1016/j.bmc. 2012.10.009

Kinae, N., Msuda, H., Shin, I. S., Furugori, M., and Shimoi, K. (2000). Functional properties of wasabi and horseradish. Bio Factors. 13, 265-269. doi: 10.1002/ biof.5520130140

Lee, Y. S., Yang, J. H., Bae, M. J., Yoo, W. K., Ye, S., Xue, C. C., et al. (2010). Anti-oxidant and anti-hypercholesterolemic activities of wasabia japonica. Evid. Based Complement. Altern. Med. 7, 459-464. doi: 10.1093/ecam/nen038

Li, H., and Gänzle, M. (2016). Effect of hydrostatic pressure and antimicrobials on survival of Listeria monocytogenes and enterohaemorrhagic Escherichia coli in beef. Innov Food Sci. Emerg. Technol. 38, 321-327. doi: 10.1016/j.ifset.2016.05. 003

Lin, C. M., Preston, J. E. III, and Wei, C. I. (2000). Antibacterial mechanism of allyl isothiocyanate. J. Food Prot. 63, 727-734. doi: 10.4315/0362-028X-63.6.727

Liu, Y., Betti, M., and Gänzle, M. G. (2012). High pressure inactivation of Escherichia coli, Campylobacter jejuni, and spoilage microbiota on poultry meat. J. Food Prot. 75, 497-503. doi: 10.4315/0362-028X.JFP-11-316

Liu, Y., Gill, A., McMullen, L., and Gänzle, M. G. (2015). Variation in heat and pressure resistance of verotoxigenic and nontoxigenic Escherichia coli. J. Food Prot. 78, 111-120. doi: 10.4315/0362-028X.JFP-14-267

Lu, Z., Dockery, C. R., Crosby, M., Chavarria, K., Patterson, B., and Giedd, M. (2016). Antibacterial activities of wasabi against Escherichia coli O157:H7 and Staphylococcus aureus. Front. Microbiol. 7:1403. doi: 10.3389/fmicb.2016.01403

Luciano, F. B., and Holley, R. A. (2009).Enzymatic inhibition by allyl isothiocyanate and factors affecting its antimicrobialaction against Escherichia coli O157:H7. Int. J. Food Microbiol. 131, 240-245. doi: 10.1016/j.ijfoodmicro.2009.03.005

Luscher, C., Balasa, A., Fröhling, A., Ananta, E., and Knorr, D. (2004). Effect of high-pressure-induced ice I-to-ice III phase transitions on inactivation of Listeria innocua in frozen suspension. Appl. Environ. Microbiol. 70, 4021-4029. doi: 10.1128/AEM.70.7.4021-4029.2004

Maresca, P., and Ferrari, G. (2013). "Novel applications of high hydrostatic pressure on foodstuffs: High pressure freezing," in Advances in Engineering Research, Vol. 7, ed. V. M. Petrova (Hauppauge, NY: Nova Science Publishers, Inc.), 1-46.

Maresca, P., and Ferrari, G. (2017). Modeling of the microbial inactivation by high hydrostatic pressure freezing. Food Control. 73, 8-17. doi: 10.1016/j.foodcont. 2016.05.047

Massaux, C., Béra, F., Steyer, B., Sindic, M., and Deroanne, C. (1999). "High hydrostatic pressure freezing and thawing of pork meat: quality preservation, processing times and high pressure treatment advantages," in Advanced in High Pressure Bioscience and Biotechnology, ed. H. Ludwig (Berlin Heidelberg: Springer-Verlag), 485-488.

McArdle, R., Marcos, B., Kerry, J. P., and Mullen, A. (2010). Monitoring the effects of high pressure processing and temperature on selected beef quality attributes. Meat Science. 86, 629-634. doi: 10.1016/j.meatsci.2010.05.001

McArdle, R., Marcos, B., Kerry, J. P., and Mullen, A. (2011). Influence of HPP conditions on selected beef quality attributes and their stability during chilled storage. Meat Sci. 87, 274-281. doi: 10.1016/j.meatsci.2010.10.022

Merck \& Co., Inc (2006). Allyl Isothiocyanate in The Merck Index: An Encyclopedia of Chemicals, Drugs, and 979 Biologicals, 14th Ed. Whitehouse Station, NJ: Merck \& Co., Inc.

Moon, H., and Rhee, M. S. (2016). Synergism between carvacrol or thymol increases the antimicrobial efficacy of soy sauce with no sensory impact. Int. J. Food Microbiol. 217, 35-41. doi: 10.1016/j.ijfoodmicro.2015.10.009

National Advisory Committee on Microbiological Criteria for Food [NACMCF] (2006). Requisite scientific parameters for establishing the equivalence for alternative methods of pasteurization. J. Food Prot. 69, 1190-1216.

Olsen, N. V., Grunert, K. G., and Sonne, A.-M. (2010). Consumer acceptance of high-pressure processing and pulsed-electric field: a review. Trends Food Sci. Technol. 21, 464-472. doi: 10.1016/j.tifs.2010.07.002

Omer, M. K., Alvseike, O., Holck, A., Axelsson, L., Prieto, M., Skjerve, E., et al. (2010). Application of high pressure processing to reduce verotoxigenic E. coli in two types of dry-fermented sausage. Meat Sci. 86, 1005-1009. doi: 10.1016/j. meatsci.2010.08.008

Park, H. W., Choi, K. D., and Shin, I. S. (2013). Antimicrobial activity of isothiocyanates (ITCs) extracted from horseradish (Armoracia rusticana) root against oral microorganisms. Biocontrol Sci. 18, 163-168. doi: 10.4265/bio. 18.163

San Martín, M. F., Barbosa-Canovas, G. V., and Swanson, B. G. (2002). Food processing by high hydrostatic pressure. Crit. Rev. Food Sci. Nutr. 42, 627-645. doi: $10.1080 / 20024091054274$

Sheen, S., Cassidy, J., Scullen, O., and Sommers, C. (2015). Inactivation of agenetically diverse set of Shigatoxin-producing Escherichia coli in ground beef using high pressure processing. Food Microbiol. 52, 84-87. doi: 10.1016/j.fm. 2015.07.001

Sheen, S., Huang, C. Y., Ramos, R., Chien, S. Y., Scullen, B., and Sommers C. (2018). Lethality prediction for Escherichia coli O157:H7 and Uropathogenic E. coli in ground chicken treated with high pressure processing and trans-cinnamaldehyde. J Food Sci. 83, 740-749. doi: 10.1111/1750-3841. 14059

Simonin, H., Duranton, F., and de Lamballerie, M. (2012). New insights into the high-pressure processing of meats and meat products. Comprehen. Rev. Food Sci. Food Saf. 11, 285-306. doi: 10.1111/j.1541-4337.2012. 00184.x

Sommers, C. H., Scullen, O. J., and Sheen S. (2016). Inactivation of uropathogenic Escherichia coli in ground chicken meat using high pressure processing and gamma radiation, and in purge and chicken meat surfaces by ultraviolet light. Front. Microbiol. 7:413. doi: 10.3389/fmicb.2016.00413

Somolinos, M., García, D., Pagán, R., and Mackey, B. (2008). Relationship between sublethal injury and microbial inactivation by the combination of high hydrostatic pressure and citral or tert-butyl hydroquinone. Appl. Environ. Microbiol. 74, 7570-7577. doi: 10.1128/AEM.00936-08

Sultana, T., Savage, G. P., Mc Neil, D. L., Porter, N. G., and Martin, R. J. (2000). Flavour compounds in the rhizome of soil-grown wasabi. Proc. Nutr. Soc. N. Z. $25,95-106$.

Urrutia, G., Arabas, J., Autio, K., Brul, S., Hendrickx, M., Kakolewski, A., et al. (2007). SAFE ICE: low-temperature pressure processing of foods: safety and quality aspects, process parameters and consumer acceptance. J. Food Eng. 83, 293-315. doi: 10.1016/j.jfoodeng.2007.03.004

USDA Food Safety, and Inspection Service [FSIS] (2012). Risk Profile for Pathogenic non-O157 Shiga toxin-producing Escherichia coli. Office (of )Public Health Science, Office of Policy and Program Development, Food Safety and Inspection Service, Washington, D.C.: United States Department of Agriculture.

Vaux, D. L., Fidler, F., and Cumming, G. (2012). Replicates and repeats - what is the difference and is it significant? EMBO Rep. 13:291-296. doi: 10.1038/embor. 2012.36

Wesche, A. M., Gurtler, J. B., Marks, B. P., and Ryser, E. T. (2009). Stress, sublethal injury, resuscitation, and virulence of bacterial foodborne pathogens. J. Food Prot. 72, 1121-1138. doi: 10.4315/0362-028X-72.5.1121

Yuste, J., Capellas, M., Fung, D. Y. C., and Mor-Mur, M. (2004). Inactivation and sublethal injury of foodborne pathogens by high-pressure processing: evaluation with conventional media and thin-agar layer method. Food Res. Int. 37, 861-866. doi: 10.1016/j.foodres.2004.05.002

Zhang, Y., Tang, L., and Gonzalez, V. (2003). Selected isothiocyanates rapidly induce growth inhibition of cancer cells. Mol. Cancer Ther. 2, 1045-1052.

Zhou, S., Sheen, S., Pang, Y. H., Liu, L., and Yam, K. L. (2015). Modeling the impact of vapor thymol concentration, temperature, and modified atmosphere condition on growth behavior of Salmonella on raw shrimp. J. Food Prot. 78, 293-301. doi: 10.4315/0362-028X.JFP-14-264

Disclaimer: Mention of trade names or commercial products in this publication is solely for the purpose of providing specific information and does not imply recommendation or endorsement by the United States Department of Agriculture. USDA is an equal opportunity provider and employer.

Conflict of Interest Statement: The authors declare that the research was conducted in the absence of any commercial or financial relationships that could be construed as a potential conflict of interest.

Copyright $\odot 2018$ Huang, Sheen, Sommers and Sheen. This is an open-access article distributed under the terms of the Creative Commons Attribution License (CC BY). The use, distribution or reproduction in other forums is permitted, provided the original author(s) and the copyright owner(s) are credited and that the original publication in this journal is cited, in accordance with accepted academic practice. No use, distribution or reproduction is permitted which does not comply with these terms. 